\title{
The relationship between disordered eating and sexuality amongst adolescents and young adults
}

\author{
Annie Shearer *, Jody Russon, Joanna Herres, Tita Atte, Tamar Kodish, Guy Diamond \\ Drexel University, United States
}

\section{A R T I C L E I N F O}

\section{Article history:}

Received 30 January 2015

Received in revised form 29 May 2015

Accepted 12 August 2015

Available online 18 August 2015

\section{Keywords:}

Eating behaviors

Sexuality

Adolescence

Young adulthood

\begin{abstract}
A B S T R A C T
Research shows that gay and bisexual males are at increased risk for disordered eating symptoms (DES); however, studies examining DES amongst lesbians and bisexual women have produced mixed findings. Furthermore, few studies have included questioning or "unsure" individuals. This study examined DES symptoms in adolescents and young adults across self-reported sexual attraction and behavior. Participants were recruited from ten primary care sites in Pennsylvania and administered the Behavioral Health Screen (BHS) - a web-based screening tool that assesses psychiatric symptoms and risk behaviors - during a routine visit. As expected, males who were attracted to other males exhibited significantly higher disordered eating scores than those only attracted to members of the opposite sex. Males who engaged in sexual activities with other males also exhibited significantly higher scores than those who only engaged in sexual activities with females. Amongst females, there were no significant differences in DES scores between females who were only attracted to females and those only attracted to males. Those who reported being attracted to both sexes, however, had significantly higher scores, on average, than those only attracted to one sex. More surprisingly, females who were unsure of who they were attracted to reported the highest DES scores of all. These findings are contrary to previous assumptions that same-sex attraction plays a protective role against eating pathology in females. Females who are unsure or attracted to both sexes may actually be at increased risk for developing DES.
\end{abstract}

(C) 2015 Elsevier Ltd. All rights reserved.

\section{Introduction}

Anorexia nervosa (AN), bulimia nervosa (BN), and binge eating disorder (BED) typically emerge during adolescence, affecting roughly $0.3 \%, 0.9 \%$, and $1.6 \%$ of youth living in the United States, respectively (Swanson, Crow, Le Grange, Swendsen, \& Merikangas, 2011). The early ages of onset for these disorders are particularly troubling given the numerous deleterious effects of eating disorders (EDs) and disordered eating symptoms (DES). AN has one of the highest mortality rates of any psychiatric disorder, taking the lives of 5.6\% of sufferers each decade (Sullivan, 1995). This heightened mortality is attributed not only to starvation but also to an increased risk of suicide (Bulik et al., 2008). ED sufferers also exhibit elevated rates of psychiatric co-morbidity compared with the general population (O'Brien \& Vincent, 2003).

Lesbian, gay, bisexual, and questioning (LGBQ) adolescents also experience increased risk of psychiatric problems, including anxiety, depression, and suicidal ideation (D'augelli, 2002). Amongst men,

* Corresponding author at: Center for Family Intervention Science, 3020 Market St, Suite 510, Philadelphia, PA 19104, United States. Tel.: + 1215571 3425; fax: + 1215 5713411.

E-mail address: ams694@drexel.edu (A. Shearer). being gay or bisexual has consistently been shown to increase one's susceptibility to EDs (e.g., Feldman \& Meyer, 2007; Russell \& Keel, 2002). Two theories in particular have been used to explain this phenomenon. The first, Objectification Theory, which was originally developed to explain the female gender bias in EDs and body shame, emphasizes the sociocultural factors that contribute to ED symptomatology. Specifically, Objectification Theory argues that women experience greater societal pressure to appear thin and attractive, resulting in a female gender bias for EDs (Fredrickson \& Roberts, 1997). Further, the theory states that internalization of these unrealistic standards can result in body shame and consequently, disordered eating. Because men value physical attractiveness more than women, GB men may face similar sociocultural pressures to heterosexual women (Beren, Hayden, Wilfley, \& Grilo, 1996). Indeed, peer pressure related to physical appearance and body dissatisfaction is stronger for gay men than heterosexual men (Hospers and Jansen, 2005).

Another theory that may explain the association between sexual identity and DES is the minority stress hypothesis, which states that minority groups such as LGBQ individuals are at increased risk for mental health problems as a result of stress caused by societal stigmatization (Meyer, 2003). For LGBQ individuals, this stress manifest as: 1) external, objective stressors, such as antigay discrimination; b) the expectation of prejudice, resulting in vigilant monitoring; and c) internalization of 
stigma and prejudice (e.g., internalized homophobia). These factors (not identity itself) account for higher rates of mental health problems in LGBQ populations.

The increased risk of EDs amongst GB men has led some to hypothesize that lesbians should be protected from these issues (Guille \& Chrisler, 1999; Siever, 1994). This assumes that lesbians are more immune from sociocultural norms related to attractiveness than heterosexual women. However, all women, regardless of identity, are exposed to societal messages that promote the association between one's appearance and one's self-worth (Bartky, 1990). Indeed, researchers have found no significant differences between lesbians and heterosexual women on endorsement of sociocultural norms regarding thinness and attractiveness or on perceived sociocultural pressure for thinness (Heffernan, 1996; Strong, Williamson, Netemeyer, \& Geer, 2000). Moreover, the media frequently exploits female same-sex sexuality as a way of enticing male viewers (Brewster \& Moradi, 2010). This type of objectification is unique to LGBQ women. In addition, LGBQ adolescent females report more sexual harassment than their heterosexual peers, which may further contribute to body shame and disordered eating (Mitchell, Ybarra, \& Korchmaros, 2014; Williams, Connolly, Pepler, \& Craig, 2005). Although gender is a primary factor in exposure to objectification experiences, LGBQ men and women may experience these sociocultural pressures in a distinctive way.

Overall, research on LGBQ women and DES has demonstrated mixed findings. For example, a few early studies found that lesbians experience lower rates of body dissatisfaction and DES than heterosexual women (Guille \& Chrisler, 1999; Siever, 1994), while others found no differences between the two groups (e.g., Beren et al., 1996; Feldman \& Meyer, 2007; Heffernan, 1996; Moore \& Keel, 2003; Share \& Mintz, 2002). More recently, a number of studies suggest that LGBQ females, like LGBQ males, may be at increased risk for ED behaviors and/or unhealthy weight control practices during adolescence and young adulthood (e.g., Austin et al., 2009; Hadland, Austin, Goodenow, \& Calzo, 2014; Robin et al., 2002; Wichstrøm, 2006). For instance, in one sample, adolescents who identified as gay/lesbian, bisexual, and "mostly heterosexual," reported higher past-year rates of binge eating compared to their heterosexual peers. In addition, gay, bisexual, and "mostly heterosexual" males as well as "mostly heterosexual" and bisexual females were more likely to report purging than their heterosexual peers (Austin et al., 2009). In another sample of Massachusetts high school students, LGB students were also more likely to engage in unhealthy weight control behaviors than their heterosexual peers (Hadland et al., 2014). Same-sex sexual experiences have also been shown to predict bulimic symptoms five years later for both genders (Wichstrøm, 2006).

Although researchers are increasingly recognizing bisexual persons as a distinct subgroup, questioning or "unsure" individuals continue to be overlooked. Even when data are collected on these groups, researchers have often chosen to exclude them from analyses (e.g., Austin et al., 2004, 2009; Boehmer, Bowen, \& Bauer, 2007; Hadland et al., 2014), despite evidence that, like their LGB peers, these adolescents are at increased risk of suicidality and other psychosocial problems (Williams, Connolly, Pepler, \& Craig, 2005; Zhao, Montoro, Igartua, \& Thombs, 2010). Given that sexual identity development is critical in adolescence and young adulthood, questioning samples may be especially important for studying disorders that emerge during this time. One exception is a study that examined ED behaviors amongst U.S. college students (Matthews-Ewald, Zullig, \& Ward, 2014). They found that unsure, gay, and bisexual males were more likely to report ED behaviors and unsure, gay, and bisexual females were more likely to report dieting than their heterosexual peers. Another study conducted with college students found that gay and unsure males were more likely to engage in unhealthy weight control behaviors than heterosexual males (Laska et al., 2015).

The purpose of the present study is to examine DES across sexual minority adolescents and young adults. We have also included an unsure group (Laska et al., 2015; Matthews-Ewald et al., 2014) in light of the pressures of sexual identity formation faced by these age groups (Rosario, Schrimshaw, Hunter, \& Braun, 2006). Based on past findings, we hypothesized that 1 ) males reporting same-sex attraction would exhibit higher rates of DES than opposite-sex attracted males, and 2) there would be no differences amongst females, regardless of attraction. We did not have a hypothesis regarding the unsure group given the paucity of literature for this population. Since sexuality is a complex (Diamond, 2000), we also examined DES and sexual behavior. We hypothesized that 1) males who engage in sexual behavior with other males or with both sexes would exhibit more DES than males who only engage in sexual behavior with females, and 2) there would be no differences between females, regardless of behavior.

\section{Materials and methods}

\subsection{Participants}

Participants in the present study were 2513 youth (61.2\% female), ages 14 to $24(M=17.24, S D=2.86)$. The majority of the sample racially identified as White; however, some identified as Biracial (8.1\%), Black/African American (4.7\%), Asian (1.8\%), "Other" (1.5\%), "Not Sure" $(7.6 \%)$ or chose not to disclose their race $(1.5 \%)$, and $16.6 \%$ also identified as Hispanic. Finally, $91.7 \%$ of the sample was attracted to the opposite sex, $3.9 \%$ was attracted both sexes, $1.6 \%$ was unsure of who they were attracted to, and $2.0 \%$ was attracted to the same sex $(1.2 \%$ were females attracted to females and $0.8 \%$ were males attracted to males specifically). Seventeen participants' (0.7\%) self-reported attraction could not be determined due to missing data.

\subsection{Procedure}

The data were collected as part of a behavioral health-screening program in primary care. Ten primary care sites, spanning rural to semiurban areas in the northeastern part of Pennsylvania, participated. At participating sites, the screening tool - the Behavioral Health Screen (BHS) - was administered prior to their exam. Although we encouraged clinicians to screen universally, administration was ultimately left to their discretion.

\subsection{Measure}

The BHS was designed to screen for behavioral health problems using questions derived from the Diagnostic and Statistical Manual of Mental Disorders, 4th Edition, Text Revision (DSM-IV-TR) criteria. It is comprised of a total of 13 modules, which assess the following areas: demographics, medical, school, family, safety, substance use, sexuality, nutrition and eating, anxiety, depression, suicide, psychosis, and trauma and abuse (Jenkins, Singer, Conner, Calhoun, \& Diamond, 2014). There are 55 core questions across these domains, and responses are coded on a three-point scale (0-2), with a score of 0,1 , or 2 (no symptoms, moderate symptoms, and severe symptoms, respectively). A twentymember group of national experts and local focus groups consisting of medical practitioners helped select the items.

Extensive psychometric validation has confirmed the validity and reliability of the scales. For instance, in a sample of 415 adolescents recruited from primary care, the scale exhibited both good discriminant validity and good internal consistency (Diamond et al., 2010). In addition, the subscales showed good sensitivity and specificity, with overall accuracy ranging from 78 to $85 \%$. Moreover, implementation in an emergency department significantly increased the percentage of mental illness or behavioral problems identified, from $2.5 \%$ to $10.5 \%$ ( $O R=4.58$, $95 \% \mathrm{CI}=3.53$, 5.94; Fein et al., 2010).

\subsubsection{Eating behavior}

A DES score was calculated for each of the participants based on the responses to the following four questions: 1) How often do you think 
that you are fat even though some people say that you are skinny?; 2) How often do you try to control your weight by skipping meals?; 3) How often do you try to control your weight by making yourself throw up; and 4) How do you have trouble stopping eating once you've started? The first item assesses the disturbance in body weight criteria seen in both BN and AN while the second maps on to the restriction criteria that also characterizes AN. The last two map on to the bingepurge cycles that characterize BN. However, we did not collect data on BMI so we could not determine if participants were underweight as seen in AN. Also, we did not assess how often binging or purging occurred, which is necessary to make a diagnosis of BN. We also did not ask about other types of purging, such as use of laxatives, diuretics, or over-exercise. In this sample, the internal reliability was moderate (Cronbach's $\alpha=0.61$ ).

\subsubsection{Sexual attraction and behavior}

Sexual attraction was computed based on participant's gender and to which sex participants reported they felt most attracted to: either males, females, both, or not sure. A second question was used to define sexual behavior. Participants were asked whom they had engaged in sexual activities: males, females, or both (if sexually active). We computed three groups for each gender - those who only engaged in same-sex sexual behavior, those who only opposite-sex sexual behavior, and those who engaged in sexual activities with both sexes. Those who did not report being sexual active were excluded from these analyses

\section{Results}

\subsection{Sexual attraction}

On average, females ( $M=0.76, S D=0.77$ ) reported a significantly higher mean for DES scores than males $(M=0.34, S D=0.55)$, $p<.001$. A univariate analysis of variance was used to compare the effects of sexual attraction, gender, and their interaction term on mean DES score. The interaction term was significant, $F(2,2468)=5.89, p<$. $005, \eta_{p}{ }^{2}=0.005$, so we ran separate univariate analyses of variance to compare the effects of sexual attraction on mean DES score for males and females separately. As expected, there was a significant effect of attraction on mean DES score for males, $F(3,965)=14.38, p<.001$, $\eta_{p}{ }^{2}=0.043$. Specifically, males who reported same-sex attraction $(M=0.98, S D=1.01)$ or attraction to both sexes $(M=0.78, S D=$ 1.17) endorsed significantly higher mean DES scores than males who reported opposite-sex attraction $(M=0.32, S D=0.5), p<.001, d=$ 0.82 and $p<.001, d=0.51$, respectively. Similarly, they endorsed significantly higher mean DES scores than unsure males $(M=0.23, S D=$ 0.39 ), $p<.001, d=0.98$ and $p<.001, d=0.63$, respectively (see Fig. 1 ).

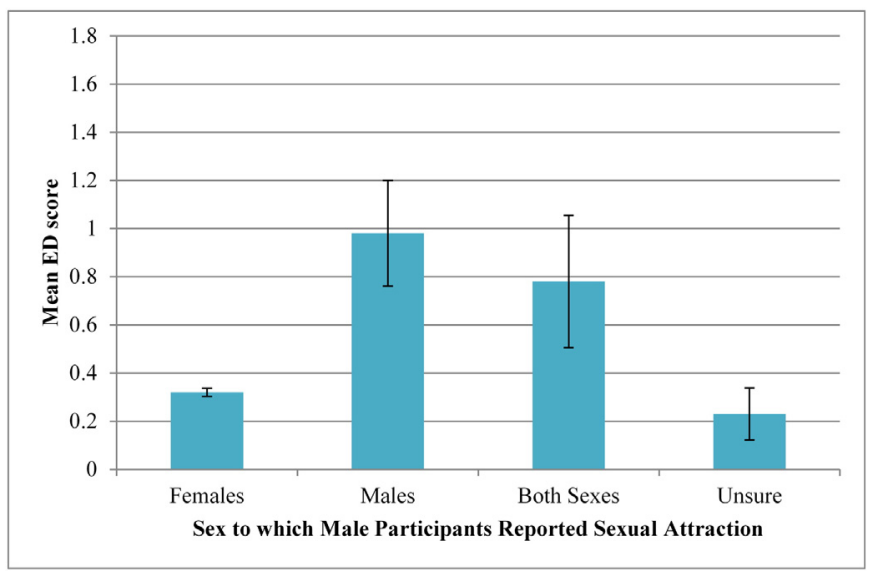

Fig. 1. Mean disordered eating symptom (DES) score by sexual attraction for males.
There was also an effect sexual attraction on mean DES score for females, $F(3,1529)=12.827, p<.001, \eta_{p}{ }^{2}=0.025$. As hypothesized, there were no significant differences between females only attracted to males $(M=0.73, S D=0.74)$ and those only attracted to females $(M=0.63, S D=0.75), p=.456, d=0.14$. Females attracted to both sexes, however, endorsed significantly higher mean DES scores $(M=$ $1.09, S D=0.86)$ than those only attracted to males or females, $p<.001, d=0.44$ and $p<.001, d=0.56$, respectively. Surprisingly, unsure females reported the highest DES scores of all $(M=1.41, S D=$ 1.10 - significantly higher than those attracted to only males or females, $p<.001, d=0.72$ and $p<.001, d=0.83$, respectively, with a trend toward higher scores than those attracted to both sexes, $p=$ $0.051, d=0.33$ (see Fig. 2).

\subsection{Sexual behavior}

Of sexually-active females, $90 \%$ reported engaging in sexual activities solely with males, $1.6 \%$ solely with females, and $8.4 \%$ with both sexes. Similarly, $95.2 \%$ of sexually-active males reported engaging in sexual activity with only females, $2.5 \%$ with only males, and $2.3 \%$ with both sexes. Again, an initial univariate analysis of variance also revealed a significant interaction between gender and sexual behavior, $F(2,1162)=5.241, p<.05, \eta_{p}^{2}=0.009$, on DES score. Additional univariate analyses of variance were run to compare the effect of sexual behavior on DES by gender. The analysis revealed no main effect for females, $F(3,771)=0.990$, ns. However, there was a significant effect amongst males, $F(3,392)=12.794, p<.001, \eta_{p}{ }^{2}=0.089$. Pairwise comparisons indicated that males who engaged sexual activities with females only reported significantly lower mean DES scores $(M=0.347$, $S D=0.52)$ than those who participated in sexual activities with only males $(M=1.40, S D=1.08)$ or both sexes $(M=0.833, S D=1.50)$, $p<.001, d=1.25$ and $p<.05, d=0.44$, respectively. In addition, males who reported engaging in sexual activities with males only reported significantly higher mean DES scores than males who reported engaging with both sexes, $p<.05, d=0.44$ (see Fig. 3 ).

\section{Discussion}

Consistent with past findings, we found that males who reported attraction to other males endorsed significantly higher mean DES scores than those only attracted to females. Similarly, males who had engaged in same-sex sexual behavior endorsed significantly higher mean scores than those who had only done so with females. These findings have frequently been explained using Objectification Theory: like heterosexual women, gay men experience greater sociocultural pressures to appear thin or attractive. Indeed, Wiseman and Moradi (2010) found that

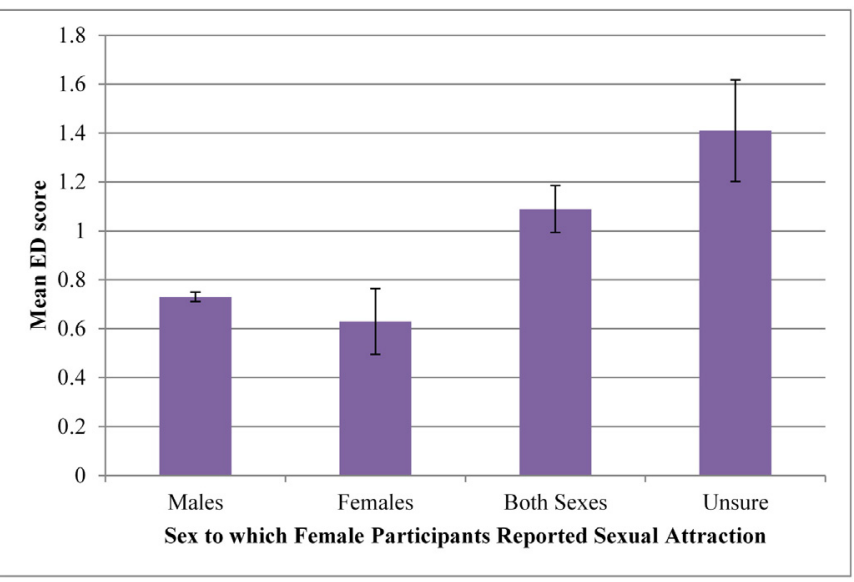

Fig. 2. Mean disordered eating symptom (DES) score by sexual attraction for females. 


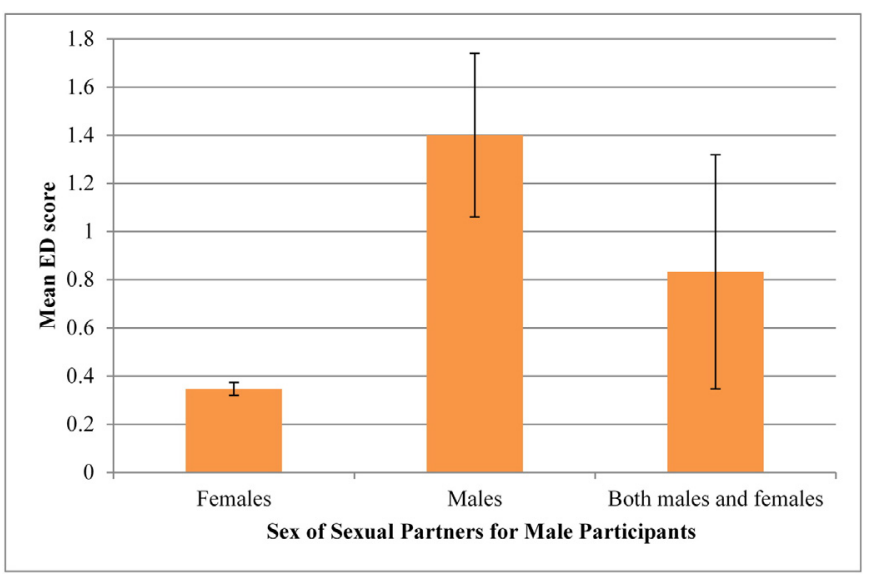

Fig. 3. Mean disordered eating symptom (DES) score by sexual behavior for males.

Objectification Theory holds for gay men as well. When viewed in tandem with the minority stress hypothesis, this theory could account for our findings as well.

In contrast to some previous findings, females reporting oppositesex attraction and same-sex attraction exhibited no differences in DES. Surprisingly, we did find that females reporting attraction to both sexes had significantly higher mean DES scores in the current sample than females who disclosed only attraction to one sex. Females who were unsure of who they were attracted to exhibited the highest number of DES of all.

It is not entirely clear why females who reported bisexual attractions or uncertainty in terms of their attractions had significantly higher mean DES on average than those reporting single-sex attractions. There is some research suggesting that those with EDs, particularly AN, experience feelings of shame and disgust regarding puberty and sexuality (Ruuska, Kaltiala-Heino, Kovisto, \& Rantanen, 2003). Moreover, in addition to stigmas associated with LGBQ identities in general, bisexual individuals face unique types of prejudice and stigma not attributed to lesbians or gay persons. Specifically, they experience three types of prejudice: 1) sexual orientation instability (i.e., bisexuality is not a legitimate identity); 2) sexual irresponsibility (i.e., bisexuals are more promiscuous); and 3) general interpersonal hostility (i.e., being disliked as a result of their sexual identity; Brewster \& Moradi, 2010). Given this stigma, perhaps bisexual females are taught that their sexuality is "not okay" and use disordered eating as a way to cope with negative feelings. Indeed, bisexual individuals report experiencing prejudice from gay/lesbian communities as well (Brewster \& Moradi, 2010). Moreover, bisexual women are more likely to be victims of sexual violence than lesbians or heterosexual women (Walters, Chen, \& Breiding, 2013). Sexual violence has also been linked to DES amongst adolescent girls (Thompson, Wonderlich, Crosby, \& Mitchell, 2001).

Finally, there is research suggesting that gay community involvement plays a protective role against DES in women (e.g., Heffernan, 1996). If these communities stigmatize bisexual women, they cannot benefit in this way. Unsure youth may also have less access to these benefits since they too may be less involved with LGB communities. In addition, this struggle to identify, coupled with the pressures of heteronormative identity development, may also help explain why the unsure females in our sample were most at risk for DES. In fact, in a meta-analysis exploring the risk factors of EDs, Polivy and Herman (2002) highlight problems of identity and personal control as some of the primary individual risk factors that contribute to the development of EDs. Unsure females may try to resolve their feelings of uncertainty by controlling their food intake and/or "the pursuit of slimness" (p. 195) - an area they can seemingly gain control and mastery.

\subsection{Limitations}

Despite these interesting results, the study is not without limitations. First, the sample may not be representative of the general population. Although the primary care sites were encouraged to screen universally, some sites only screened participants when they were concerned about the patient. In addition, not all participants may have disclosed the truth about their sexual attractions and behaviors on the screener - particularly given possible stigma. Second, sexual identity is complex and thus, difficult to capture using a brief screen. In this study, we only collected data on attraction and sexual partners - only two components of sexuality. Participants were also not allowed to self-identify but only report on behavior and attraction. In reality, sexual identity involves attraction and interpersonal contact on emotional, physical, and cognitive levels. We also did not ask about the number of times an individual has slept with either or both genders, which is also a limitation. Number of partners, particularly number by gender, could also play a role in contributing to eating pathology, and differences in the number of sexual partners by gender may be of particular importance. For instance, adolescents who engage in sexual experimentation and/or risk behaviors may also be more prone to engaging in risky eating behaviors. Future studies should allow participants to fully self-identify as well as ask about number of sexual partners by gender to capture a more nuanced and accurate picture of sexual attraction and behavior.

The DES items on the BHS may also be more representative of the thin ideal rather than the lean, muscular ideal more applicable to men, which could influence the capacity of the tool to assess DES amongst males. Furthermore, we did not collect data about transgender identities. Transgender men and women may experience a unique set of body concerns. Future studies should take pains to include these groups in order to better understand their experiences with ED symptoms. Finally, although we have attempted to outline some reasons why bisexual and unsure or questioning females were most at risk for symptoms of EDs than other females in our sample, these results were unexpected. Future research should test some of these hypotheses in order to account for why these differences exist.

\section{Conclusions}

Overall, the findings of this study address an important issue regarding sexuality and health during adolescence and early adulthood. These results suggest that females attracted to the same sex are just as likely to experience DES as their peers with opposite-sex attractions. Even more noteworthy, those attracted to both sexes exhibited higher rates of DES than their peers with only single-sex attractions. Furthermore, in this sample, it was females who were uncertain about their attraction who demonstrated the highest rates of DES of all. These findings underscore the importance of recognizing these distinct subgroups in research and in practice. Given the severe physical and emotional repercussions of EDs, it is important for researchers, mental health clinicians, and primary care physicians alike to be aware of the differences in symptom rates across young LGBQ individuals. Practitioners should aim to understand the sociocultural risk factors involved in the development of EDs amongst adolescents and young adults through consistent and accurate assessments.

\section{Role of funding sources}

Funding for this study was provided by SAMHSA under grant number SM58386. They had no role in the study design, collection, analysis or interpretation of the data, writing the manuscript, or the decision to submit the paper for publication.

\section{Contributors}

Contributions: Preliminary review of the literature and preparation of the manuscript (Annie Shearer); revision of the manuscript (Annie Shearer, Tamar Kodish, Jody Russon, and Joanna Herres); analysis (Annie Shearer, Jody Russon, and Joanna Herres); interpretation of results (Annie Shearer, Jody Russon, and Joanna Herres); research conception and 
design (Guy Diamond, Tita Atte); collection of data (Tita Atte); writing (all authors): revision (all authors).

\section{Conflict of interest}

Dr. Guy Diamond will receive some minor royalty payments if and when the Behavioral Health Screen (BHS), which was used to collect the data, is marketed to the public None of the other authors have any conflicts of interests to disclose.

\section{Acknowledgments}

The authors wish to thank Ms. Helen Squitieri, Ms. Amy Giarratana, and Ms. Kiera James who assisted in the proof-reading of the manuscript.

\section{References}

Austin, S.B., Ziyadeh, N.J., Corliss, H.L., Rosario, M., Wypij, D., Haines, J., et al. (2009). Sexua orientation disparities in purging and binge eating from early to late adolescence. Journal of Adolescent Health, 45(3), 238-245.

Austin, S., Ziyadeh, N., Kahn, J.A., Camargo, C.A., Jr., Colditz, G.A., \& Field, A.E. (2004). Sexual orientation, weight concerns, and eating-disordered behaviors in adolescent girls and boys. Journal of the American Academy of Child and Adolescent Psychiatry, 43(9), 1115-1123.

Bartky, S. L. (1990). Femininity and domination: Studies in the phenomenology of oppression New York, NY: Routledge.

Beren, S.E., Hayden, H.A., Wilfley, D.E., \& Grilo, C.M. (1996). The influence of sexual orientation on body dissatisfaction in adult men and women. International Journal of Eating Disorders, 20(2), 135-141.

Boehmer, U., Bowen, D.J., \& Bauer, G.R. (2007). Overweight and obesity in sexual-minority women: evidence from population-based data. American Journal of Public Health 97(6), 1134-1140.

Brewster, M.E., \& Moradi, B. (2010). Perceived experiences of anti-bisexual prejudice: Instrument development and evaluation. Journal of Counseling Psychology, 57(4), 451-468.

Bulik, C.M., Thornton, L., Pinheiro, A.P., Plotnicov, K., Klump, K.L., Brandt, H., et al. (2008) Suicide attempts in anorexia nervosa. Psychosomatic Medicine, 70(3), 378-383.

D'augelli, A.R. (2002). Mental health problems among lesbian, gay, and bisexual youths ages 14 to 21. Clinical Child Psychology and Psychiatry, 7(3), 433-456.

Diamond, L.M. (2000). Sexual identity, attractions, and behavior among young sexualminority women over a 2-year period. Developmental Psychology, 36(2), 241-250.

Diamond, G., Levy, S., Bevans, K.B., Fein, J.A., Wintersteen, M.B., Tien, A., et al. (2010). Development, validation, and utility of Internet-based, behavioral health screen for adolescents. Pediatrics, 126(1), e163-e170.

Fein, J.A., Pailler, M.E., Barg, F.K., Wintersteen, M.B., Hayes, K., Tien, A.Y., et al. (2010). Feasibility and effects of a Web-based adolescent psychiatric assessment administered by clinical staff in the pediatric emergency department. Archives of Pediatrics and Adolescent Medicine, 164(12), 1112-1117.

Feldman, M.B., \& Meyer, I.H. (2007). Eating disorders in diverse lesbian, gay, and bisexua populations. International Journal of Eating Disorders, 40(3), 218-226.

Fredrickson, B.L., \& Roberts, T.A. (1997). Objectification theory. Psychology of Women Quarterly, 21(2), 173-206.

Guille, C., \& Chrisler, J.C. (1999). Does feminism serve a protective function against eating disorders? Journal of Lesbian Studies, 3(4), 141-148.

Hadland, S.E., Austin, S.B., Goodenow, C.S., \& Calzo, J.P. (2014). Weight misperception and unhealthy weight control behaviors among sexual minorities in the general adolescent population. Journal of Adolescent Health, 54(3), 296-303.

Heffernan, K. (1996). Eating disorders and weight concern among lesbians. International Journal of Eating Disorders, 19(2), 127-138.

Hospers, H. J., \& Jansen, A. (2005). Why homosexuality is a risk factor for eating disorders in males. Journal of Social and Clinical Psychology, 24(8), 1188-1201.

Jenkins, A.L., Singer, J., Conner, B.T., Calhoun, S., \& Diamond, G. (2014). Risk for suicida ideation and attempt among a primary care sample of adolescents engaging in nonsuicidal self-injury. Suicide E Life-Threatening Behavior, 44(6), 616-628.

Laska, M.N., VanKim, N.A., Erickson, D.J., Lust, K., Eisenberg, M.E., \& Rosser, B.S. (2015). Disparities in weight and weight behaviors by sexual orientation in college students. American Journal of Public Health, 105(1), 111-121.
Matthews-Ewald, M.R., Zullig K.J., \& Ward, R.M. (2014). Sexual orientation and disordered eating behaviors among self-identified male and female college students. Eating Behaviors, 15(3), 441-444.

Meyer, I.H. (2003). Prejudice, social stress, and mental health in lesbian, gay, and bisexual populations: Conceptual issues and research evidence. Psychological Bulletin, 129(5), 674-697.

Mitchell, K.J., Ybarra, M.L., \& Korchmaros, J.D. (2014). Sexual harassment among adolescents of different sexual orientations and gender identities. Child Abuse E Neglect, 38(2), 280-295.

Moore, F., \& Keel, P.K. (2003). Influence of sexual orientation and age on disordered eating attitudes and behaviors in women. International Journal of Eating Disorders, 34(3), 370-374.

O'Brien, K.M., \& Vincent, N.K. (2003). Psychiatric comorbidity in anorexia and bulimia nervosa: nature, prevalence, and causal relationships. Clinical Psychology Review, 23(1), 57-74.

Polivy, J., \& Herman, C. P. (2002). Causes of eating disorders. Annual Review of Psychology, 53(1), 187-213.

Robin, L., Brener, N.D., Donahue, S.F., Hack, T., Hale, K., \& Goodenow, C. (2002). Associations between health risk behaviors and opposite-, same-, and both-sex sexual partners in representative samples of Vermont and Massachusetts high school students. Archives of Pediatrics and Adolescent Medicine, 156(4), 349-355.

Rosario, M., Schrimshaw, E.W., Hunter, J., \& Braun, L. (2006). Sexual identity development among lesbian, gay, and bisexual youths: Consistency and change over time. Journal of Sex Research, 43(1), 46-58.

Russell, C.J., \& Keel, P.K. (2002). Homosexuality as a specific risk factor for eating disorders in men. International Journal of Eating Disorders, 31(3), 300-306.

Ruuska, J., Kaltiala-Heino, R., Kovisto, A.M., \& Rantanen, P. (2003). Puberty, sexual development and eating disorders in adolescent outpatients. European Child E Adolescent Psychiatry, 12(5), 214-220.

Share, T.L., \& Mintz, L.B. (2002). Differences between lesbians and heterosexual women in disordered eating and related attitudes. Journal of Homosexuality, 42(4), 89-106.

Siever, M.D. (1994). Sexual orientation and gender as factors in socioculturally acquired vulnerability to body dissatisfaction and eating disorders. Journal of Consulting and Clinical Psychology, 62(2), 252-260.

Strong, S. M., Williamson, D. A., Netemeyer, R. G., \& Geer, J. H. (2000). Eating disorder symptoms and concerns about body differ as a function of gender and sexual orientation. Journal of Social and Clinical Psychology, 19(2), 240-255.

Sullivan, P.F. (1995). Mortality in anorexia nervosa. American Journal of Psychiatry, 152(7), 1073-1074.

Swanson, S.A., Crow, S.J., Le Grange, D., Swendsen, J., \& Merikangas, K.R. (2011). Prevalence and correlates of eating disorders in adolescents: Results from the national comorbidity survey replication adolescent supplement. Archives of General Psychiatry, 68(7), 714-723.

Thompson, K.M., Wonderlich, S.A., Crosby, R.D., \& Mitchell, J.E. (2001). Sexual violence and weight control techniques among adolescent girls. International Journal of Eating Disorders, 29(2), 166-176.

Walters, M.L., Chen, J., \& Breiding, M.J. (2013). The National Intimate Partner and Sexual Violence Survey (NISVS): 2010 findings on victimization by sexual orientation. Atlanta, GA: National Center for Injury Prevention and Control, Centers for Disease Control and Prevention.

Wichstrøm, L. (2006). Sexual orientation as a risk factor for bulimic symptoms. International Journal of Eating Disorders, 39(6), 448-453.

Williams, T., Connolly, J., Pepler, D., \& Craig, W. (2005). Peer victimization, social support, and psychosocial adjustment of sexual minority adolescents. Journal of Youth and Adolescence, 34(5), 471-482

Wiseman, M.C., \& Moradi, B. (2010). Body image and eating disorder symptoms in sexual minority men: A test and extension of objectification theory. Journal of Counseling Psychology, 57(2), 154-166.

Zhao, Y., Montoro, R., Igartua, K., \& Thombs, B.D. (2010). Suicidal ideation and attempt among adolescents reporting "unsure" sexual identity or heterosexual identity plus same-sex attraction or behavior: Forgotten groups? Journal of the American Academy of Child and Adolescent Psychiatry, 49(2), 104-113. 